\title{
How [FeFe]-Hydrogenase Facilitates Bidirectional Proton Transfer
}

\author{
Moritz Senger, ${ }^{\dagger}$ Viktor Eichmann, ${ }^{\dagger}$ Konstantin Laun, ${ }^{\dagger}$ Jifu Duan, ${ }^{\ddagger}$ Florian Wittkamp, ${ }^{\S}$ \\ Günther Knör, \\ and Sven Timo Stripp*,ं०0 \\ ${ }^{\dagger}$ Experimental Molecular Biophysics, Department of metalloenzymes \\ ${ }^{\ddagger}$ Photobiotechnology, Faculty of Biology and Biotec that catalyze the \\ Biochemistry, Ruhr-Universität Bochum, Universitä conversion of \\ "Institute of Inorganic Chemistry, Johannes Kepler protons and \\ ${ }^{\perp}$ Fraunhofer UMSICHT, 46047 Oberhausen, Germ molecular \\ Berlin, Arnimallee 14, 14195 Berlin, Germany \\ ff Small Molecules, Faculty of Chemistry and \\ Im, Germany \\ ger Straße 69, 4040 Linz, Austria
}

Supporting Information

ABSTRACT: Hydrogenases are metalloenzymes that catalyze the conversion of protons and molecular hydrogen, $\mathrm{H}_{2}$. [FeFe]hydrogenases show particularly high rates of hydrogen turnover and have inspired numerous compounds for biomimetic $\mathrm{H}_{2}$ production. Two decades of research on the active site cofactor of $[\mathrm{FeFe}]$-hydrogenases have put forward multiple models of the catalytic proceedings. In comparison, our understanding of proton transfer is poor. Previously, residues were identified forming a hydrogen-bonding network between active site cofactor and bulk solvent; however, the exact mechanism of catalytic proton transfer remained inconclusive. Here, we employ in situ infrared difference spectroscopy on the [FeFe]-hydrogenase from Chlamydomonas reinhardtii evaluating dynamic
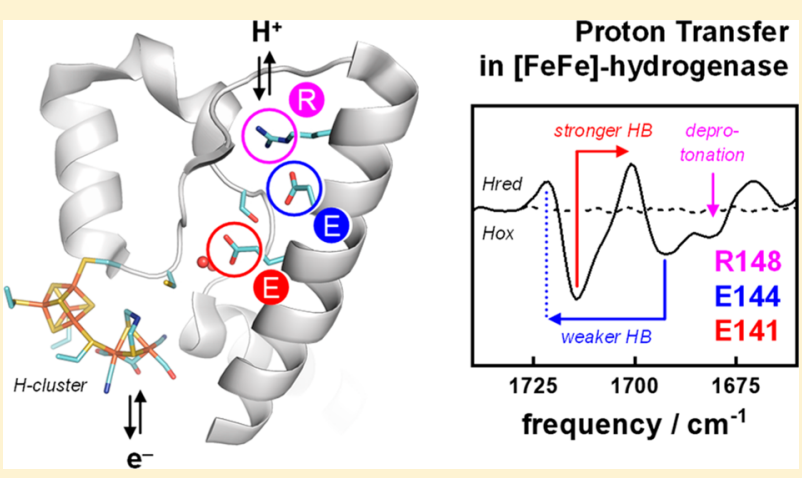
changes in the hydrogen-bonding network upon photoreduction. While proton transfer appears to be impaired in the oxidized state (Hox), the presented data support continuous proton transfer in the reduced state (Hred). Our analysis allows for a direct, molecular unique assignment to individual amino acid residues. We found that transient protonation changes of glutamic acid residue E141 and, most notably, arginine R148 facilitate bidirectional proton transfer in [FeFe]-hydrogenases.

\section{INTRODUCTION}

Hydrogenases are gas-processing iron-sulfur enzymes that catalyze the reversible reduction of protons to molecular hydrogen in all kingdoms of life. ${ }^{1,2}$ Most hydrogenases are biased toward $\mathrm{H}_{2}$ oxidation, for example, in the context of energy metabolism and $\mathrm{H}_{2}$ sensing. $^{3-5}$ The [FeFe]-hydrogenases from bacteria and algae, in contrast, are truly bidirectional and catalyze $\mathrm{H}_{2}$ oxidation and $\mathrm{H}_{2}$ evolution with similar efficiency. ${ }^{6-8}$ Combining high turnover frequencies $\left(10000 \mathrm{H}_{2} \mathrm{~s}^{-1}\right)$ and a catalytic midpoint potential close to the $\mathrm{H}^{+} / \mathrm{H}_{2}$ redox couple, ${ }^{9-11}$ the active site cofactor of $[\mathrm{FeFe}]$ hydrogenases ("H-cluster") inspired the design of numerous biomimetic complexes for $\mathrm{H}_{2}$ production. ${ }^{12-14}$

The H-cluster comprises a conventional [4Fe-4S] center linked to a bimetallic iron-sulfur complex (Figure 1a). ${ }^{15-17}$ The diiron site carries two terminal carbonyl and cyanide ligands $\left(\mathrm{CO}, \mathrm{CN}^{-}\right)$as well as a single carbonyl ligand in $\mathrm{Fe}-$ $\mathrm{Fe}$ bridging position $(\mu \mathrm{CO}) .{ }^{18-20}$ An aminodithiolate (ADT) group connects the proximal and distal iron ion $\left(\mathrm{Fe}_{\mathrm{p}}\right.$ and $\mathrm{Fe}_{\mathrm{d}}$, relative to the $[4 \mathrm{Fe}-4 \mathrm{~S}]$ center $)^{21}$ and functions as proton relay between active site cofactor and protein environment. ${ }^{22}$ While prokaryotic $[\mathrm{FeFe}]$-hydrogenases like CPI from Clostridium pasteurianum and DDH from Desulfovibrio desulfuricans hydrogenase) bind additional iron-sulfur clusters, the enzyme from Chlamydomonas reinhardtii (HYDA1) exclusively carries the H-cluster. ${ }^{6}$

During hydrogen turnover, the H-cluster adopts different redox and protonation states. The oxidized resting state $(\text { Hox })^{23-25}$ can be distinguished from intermediates with a reduced $[4 \mathrm{Fe}-4 \mathrm{~S}]$ center (Hred', Hhyd) $)^{26-32}$ or a reduced diiron site (Hred, Hsred). ${ }^{33-35}$ These states are formed upon concerted proton and electron transfer. The active-ready geometry of Hox is characterized by a square-pyramidal configuration of both metal ions, a $\mu \mathrm{CO}$ ligand, and an open coordination site at $\mathrm{Fe}_{\mathrm{d}} \cdot{ }^{15-17}$ While this geometry is conserved in Hred' and Hhyd, ${ }^{27,30}$ the structural changes upon reduction of the diiron site are under debate. ${ }^{36}$ The H-cluster may undergo rigorous ligand rearrangement forming a $\mu \mathrm{H}$ geometry, which would exclude both Hred and Hsred from catalytic turnover. ${ }^{35}$ Alternatively, diiron site geometries with a bridging $^{37,38}$ or "semi-bridging" CO ligand ${ }^{20}$ have been

Received: August 26, 2019

Published: October 3, 2019 

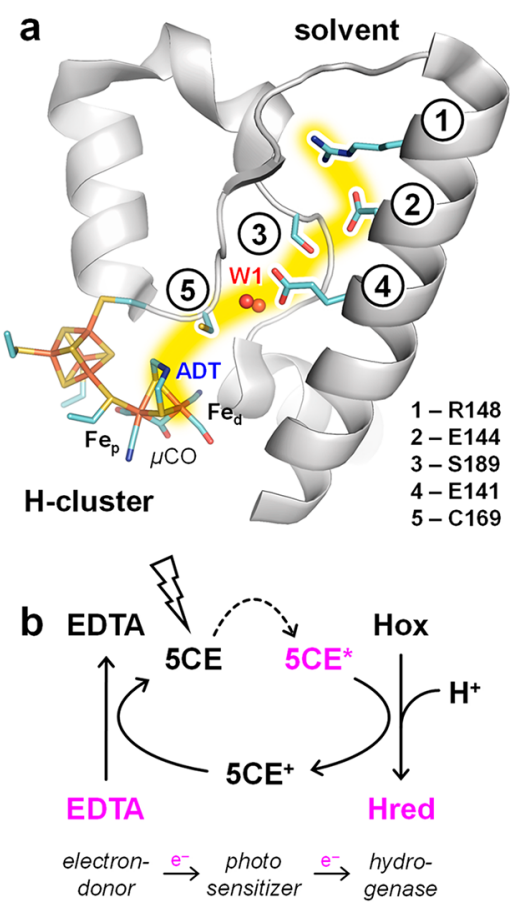

Figure 1. The proton transfer pathway of $[\mathrm{FeFe}]$-hydrogenases and experimental strategy. (a) Hydrogen turnover is catalyzed at the $\mathrm{H}$ cluster that is formed by a diiron site attached to the protein via a [4Fe-4S] center. The diiron site binds five to six $\mathrm{CO}$ and $\mathrm{CN}^{-}$ligands, one of which can be found in $\mathrm{Fe}-\mathrm{Fe}$ bridging position $(\mu \mathrm{CO})$. The ADT group functions as proton relay between C169 and the distal iron ion of the $\mathrm{H}$-cluster, $\mathrm{Fe}_{\mathrm{d}}$. Residues involved in proton transfer are identified. Cartoon model of the oxidized $[\mathrm{FeFe}]$-hydrogenase from CPI according to pdb entry $4 \mathrm{XDC}$, numbering refers to HYDA1. (b) Steady-state illumination of 5 '-carboxy eosin Y (5CE, photosensitizer) at $505 \mathrm{~nm}$ populated the excited triplet state, $5 \mathrm{CE}^{*}$. The latter was quenched by the oxidized enzyme to enrich Hred over Hox. Increasing the basicity upon reduction induces a protonation of the $\mathrm{H}$-cluster. The associated changes in the hydrogen-bonding network of the catalytic proton transfer pathway are followed by in situ ATR FTIR difference spectroscopy. The sacrificial electron donor EDTA rereduced $5 \mathrm{CE}^{+}$to $5 \mathrm{CE}$.

suggested. On the basis of the assumption of a protonated $\mathrm{ADT}$ group in these species, the nomenclature $\mathrm{HredH}^{+}$and HsredH $^{+}$can be found in literature. ${ }^{34}$

$[\mathrm{FeFe}]$-hydrogenases exchange protons with the bulk solvent via a trajectory of conserved, polar amino acid residues that connect active site cofactor and protein surface (Figure 1a). ${ }^{39-41}$ Making use of protein crystallography and infrared spectroscopy, previously we were able to identify the residues that render catalytic proton transfer possible. ${ }^{42}$ In the $[\mathrm{FeFe}]$ hydrogenase from $C$. reinhardtii, this includes R148, E144, S189, E141, C169 (numbers $1-5$ in Figure 1a), and water cluster W1. A second, mostly aqueous proton transfer pathway facilitates protonation of the $[4 \mathrm{Fe}-4 \mathrm{~S}]$ center. ${ }^{27}$ These protons are not consumed in the $\mathrm{H}_{2}$ release reaction but stabilize the active-ready geometry and compensate for the drop in redox potential after a first reduction step. ${ }^{26,32}$ The dynamics of catalytic proton transfer have been addressed by molecular dynamics simulations before; ${ }^{43-45}$ however, no experimental data exist on the changes in the hydrogen-bonding network, for example, when switching from $\mathrm{H}_{2}$ evolution to $\mathrm{H}_{2}$ oxidation. Such data are key to understanding the bidirectional catalysis of $[\mathrm{FeFe}]$-hydrogenases.
The high extinction coefficient of the active site $\mathrm{CO}$ and $\mathrm{CN}^{-}$ligands facilitated numerous investigations of the $\mathrm{H}$ cluster by Fourier-transform infrared (FTIR) spectroscopy. ${ }^{25-34}$ In chromophoric proteins, FTIR difference spectroscopy is routinely used for the analysis of light-induced proton transfer steps. ${ }^{46-48}$ However, compared to the H-cluster ligands, the involved amino acid side chains exhibit a drastically lower extinction coefficient and overlap with the intense absorption bands of liquid water and the protein backbone. [ $\mathrm{FeFe}]$-hydrogenases lack a natural chromophore to selectively trigger catalytic activity and protonation changes by light, which renders an analysis of proton transfer challenging. Redox dyes provides an opportunity to characterize hydrogenbonding networks in visibly transparent enzymes. ${ }^{49}$

Here, we explore the dynamics of proton transfer in HYDA1 using in situ attenuated total reflection (ATR) FTIR difference spectroscopy. We report steady-state photoreduction of the $\mathrm{H}$ cluster in the presence of $5^{\prime}$-carboxy eosin $\mathrm{Y}(5 \mathrm{CE})^{50}$ that resulted in a fast $\left(t_{1 / 2} \approx 20 \mathrm{~s}\right)$, near complete $(>90 \%)$, and highly selective redox conversion $(<5 \%$ other species) of the one-electron reduced state Hred over the oxidized resting state, Hox (Figure 1b). These parameters were not achieved by in situ gas treatments ${ }^{27,30}$ or electrochemical titrations. ${ }^{32,35}$ The proton uptake associated with formation of Hred induced spectral differences in the IR regime from 1750 to $1650 \mathrm{~cm}^{-1}$. Exploiting in situ H/D exchange and site-directed mutagenesis, these differences are assigned to the $\mathrm{C}=\mathrm{O}$ stretching vibrations of carboxylic acid side chains $(\mathrm{COOH})$ and the coupled vibrational mode of an protonated arginine side chain $\left(\mathrm{C}\left(\mathrm{NH}_{2}\right)_{3}{ }^{+}\right)$. Infrared spectroscopy provides evidence for changes in hydrogen bonding involving glutamic acid E141 and serine $\mathrm{S} 189$ close to the active site as well as glutamic acid E144 and arginine R148 near the protein surface. This work presents the first direct, experimental characterization of the hydrogen-bonding network that facilitates catalytic proton transfer in $[\mathrm{FeFe}]$-hydrogenases.

\section{EXPERIMENTAL SECTION}

The [FeFe]-hydrogenase from C. reinhardtii HYDA1 was expressed and synthesized in Escherichia coli, purified by strep-tactin affinity chromatography, and activated in vitro with synthetic ADT-containing diiron complex under anaerobic conditions. ${ }^{51,52}$ After removal of excess complex, the protein concentration was adjusted to $\sim 3 \mathrm{mM}$ $(\sim 150 \mathrm{~g} / \mathrm{L}) .5^{\prime}$-Carboxy eosin Y $(5 \mathrm{CE})^{50}$ and ethylenediaminetetraacetic acid (EDTA) were prepared in aqueous stock solutions of 6 and $90 \mathrm{mM}$, respectively. One part of each component was mixed to yield a HYDA1/5CE/EDTA ratio of 1:2:30.

All spectroscopic experiments were performed under anaerobic conditions, at room temperature, ambient pressure, and on hydrated protein films of physiological $\mathrm{pH}$ values. First, $1-2 \mu \mathrm{L}$ of the reaction mix was pipetted onto the silicon crystal of the ATR unit (DuraDisc SamplIR-2, Smiths Detection) in the FTIR spectrometer (Tensor 27, Bruker). Spectra from $3900-1300 \mathrm{~cm}^{-1}$ were recorded with a narrowband mercury cadmium telluride (MCT) detector with a spectral resolution of $2 \mathrm{~cm}^{-1}$ and 25 interferometer scans each $(80 \mathrm{kHz})$. The solution was protected from stray light, dried under $\mathrm{N}_{2}$, and rehydrated via the gas phase with $10 \mathrm{mM} 2$-( $N$-morpholino)ethanesulfonic acid (MES) buffer ( $\mathrm{pH} \mathrm{6)}$. Traces of reduced and $\mathrm{CO}$-inhibited species were lost in favor of Hox upon auto-oxidation. ${ }^{27}$

For the $\mathrm{pH}$ jump experiments, guanidine- $\mathrm{HCl}$ was solved in $\mathrm{H}_{2} \mathrm{O}$ or $\mathrm{D}_{2} \mathrm{O}$. Ten microliters of a $1000 \mathrm{~g} \mathrm{~L}^{-1}$ guanidine- $\mathrm{HCl}$ solution $(\mathrm{pH}$ $\approx \sim 8$ ) was pipetted onto the ATR crystal and continuously measured by FTIR spectroscopy. Addition of $1 \mu \mathrm{L}$ of $\mathrm{NaOH}$ solution $(\sim 100 \mathrm{~g}$ $\mathrm{L}^{-1}$, in $\mathrm{H}_{2} \mathrm{O}$ or $\mathrm{D}_{2} \mathrm{O}$ ) increased the bulk $\mathrm{pH}$ above the $\mathrm{pK}$ a of guanidine- $\mathrm{HCl}(\sim 13.5)$ deprotonating the guanidinium ion. 


\section{RESULTS}

The experiment was initiated upon steady-state illumination of the film at $505 \mathrm{~nm}$ and followed by FTIR spectroscopy with a time resolution of $5 \mathrm{~s}$ (up to $60 \mathrm{~s}$, see Figure S1). After $\sim 20 \mathrm{~s}$, half of the Hox population converted into Hred. Importantly, no other reduced species than Hred were observed, although $\mathrm{H}_{2}$ released upon reduction of $H Y D A 1^{50}$ may rereact with the enzyme forming Hred', Hsred, and Hhyd. Therefore, the continuous exchange of gas in our setup was found to be of particular importance, as it precludes reoxidation of $\mathrm{H}_{2}$ and a buildup of multiple reduced species. ${ }^{22}$ No photoreduction was observed under off-resonant conditions $(590 \mathrm{~nm})$, whereas illumination at $455 \mathrm{~nm}$ induced notable $\mathrm{H}$-cluster corruption (Figure S2), as noted earlier. ${ }^{53}$

Figure $2 \mathrm{a}$ shows an overlay of absorbance spectra in the range of $3900-1300 \mathrm{~cm}^{-1}$ in the dark (black) and light (magenta). The absorbance ratio of $\sim 1.3$ for amide I $(1635$ $\left.\mathrm{cm}^{-1}\right)$ to amide II $\left(1545 \mathrm{~cm}^{-1}\right)$ suggests a well-hydrated protein film. ${ }^{27}$ From 2700 to $1800 \mathrm{~cm}^{-1}$ neither liquid water $\left(\mathrm{H}_{2} \mathrm{O}\right)$ nor protein solution show strong IR intensities, which allows analyzing the $\mathrm{CO} / \mathrm{CN}^{-}$bands of the $\mathrm{H}$-cluster in absolute spectra. The inset highlights the IR signature of the $\mathrm{H}$-cluster from 2150 to $1750 \mathrm{~cm}^{-1}$. The difference spectrum in Figure $2 \mathrm{~b}$ emphasizes how the hydrogenase adopted Hox in the dark while Hred clearly dominated upon illumination. The respective IR band patterns have been identified earlier. ${ }^{34,35}$ Fitting these patterns to absolute spectra before and after illumination indicated a redox conversion larger than $90 \%$.

In contrast to the $\mathrm{CO} / \mathrm{CN}^{-}$bands, the intense absorbance of liquid water ( $\mathrm{HOH}$ bending) and protein backbone (amide I, amide II) overlaps with signals in the $\mathrm{COOH}$ regime from 1750 to $1650 \mathrm{~cm}^{-1}$ and precludes any meaningful analysis in absolute spectra. Figure $2 c$ shows a "dark-light" difference spectrum computed from the single channel spectra that generated the absorbance spectra in Figure 2a. The cofactor bands clearly dominate the spectrum. Efficient photoreduction prevents an accumulation of unspecific changes in the film (i.e., hydration level, protein concentration) and allows analyzing the full spectrum. This includes the $\mathrm{OH}, \mathrm{SH}$, and $\mathrm{COOH}$ regime as well as frequencies less than $1600 \mathrm{~cm}^{-1}$ comprising marker bands of the photosensitizer 5CE (Figure S2).

All difference bands in the $\mathrm{COOH}$ regime are specific for functional HYDA1. The inset in Figure 2c shows that no such changes were observed when HYDA1 apoprotein was probed (apo-HYDA1 lacks the diiron site and is catalytically unreactive $\left.^{51,52}\right)$. Moreover, difference spectra of HYDA1 recorded upon exposure to $\mathrm{CO}$ (Hox-CO over Hox) or in the presence of zinc porphyrin as an alternative redox dye $\mathrm{C}^{54}$ (Hred' over Hox) confirmed that all bands in the $\mathrm{COOH}$ regime are specific for the formation of Hred (Figure S3).

It is important to point out that our results do not suggest protonation or hydrogen-bonding differences involving $\mathrm{OH}$ or $\mathrm{SH}$ groups (Figure S4). The former would give rise to sharp absorbance bands around $3650 \mathrm{~cm}^{-1}$ indicative of "dangling", weakly hydrogen-bonded water. ${ }^{5,56}$ The $\mathrm{SH}$ group absorbs around $2550 \mathrm{~cm}^{-1}$ and is very sensitive to changes in hydrophilicity. ${ }^{56-58}$ Typically, this frequency regime is addressed to analyze hydrogen-bonding changes involving the side chain of a cysteine, for example, C169. Comparing our data with recent work by Hirota et al. on [NiFe]-hydrogenases $^{58}$ shows that the signal-to-noise ratio of the Hred Hox difference spectrum would allow identifying potential
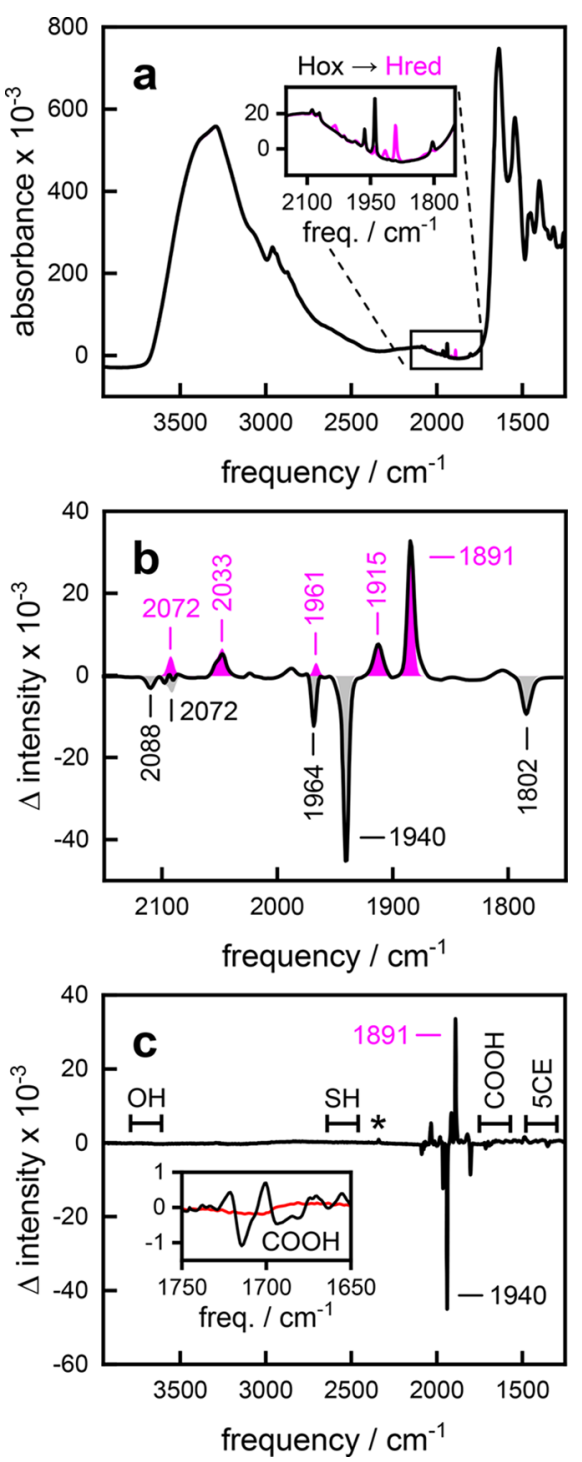

Figure 2. Absorbance and light-induced difference spectra of [FeFe]-hydrogenase. (a) ATR FTIR absorbance spectra of the hydrated reaction mixture (HYDA1/5CE/EDTA) in the dark (black) and upon illumination at $505 \mathrm{~nm}$ (magenta). (inset) Magnification of the cofactor regime $\left(2150-1750 \mathrm{~cm}^{-1}\right)$. (b) Subtraction of single channel spectra from the same data set. The dark-light difference spectrum in the $\mathrm{CO} / \mathrm{CN}^{-}$regime of the $\mathrm{H}$-cluster shows conversion of Hox (black, negative bands) into Hred (magenta, positive bands). (c) The full difference spectrum allows analyzing the $\mathrm{OH}, \mathrm{SH}$, and $\mathrm{COOH}$ regime as well as frequencies less than $1500 \mathrm{~cm}^{-1}$ comprising vibrational marker bands of photosensitizer 5CE. (inset) Magnification of the $\mathrm{COOH}$ regime. The band changes are specific for functional HYDA1 (black) and not observed in HYDA1 apoprotein (red). $* 2337 \mathrm{~cm}^{-1}$, assigned to $\mathrm{CO}_{2}$.

changes in the $\mathrm{OH}$ and $\mathrm{SH}$ regime (Figure S4). However, the lack thereof suggests an invariable hydrogen-bonding network between the water cluster W1, C169, and the ADT headgroup of the H-cluster (Figure 1a).

Band Fitting and Tentative Assignments. The Hred Hox spectrum in the $\mathrm{COOH}$ regime was described by a fit routine including a minimum of nine Gaussians with a fixed half-max width of $6-8 \mathrm{~cm}^{-1}$ and third-order polynomial baseline correction (Figure 3a). The temporal evolution of these bands is in excellent agreement with those of the $\mathrm{H}$ - 

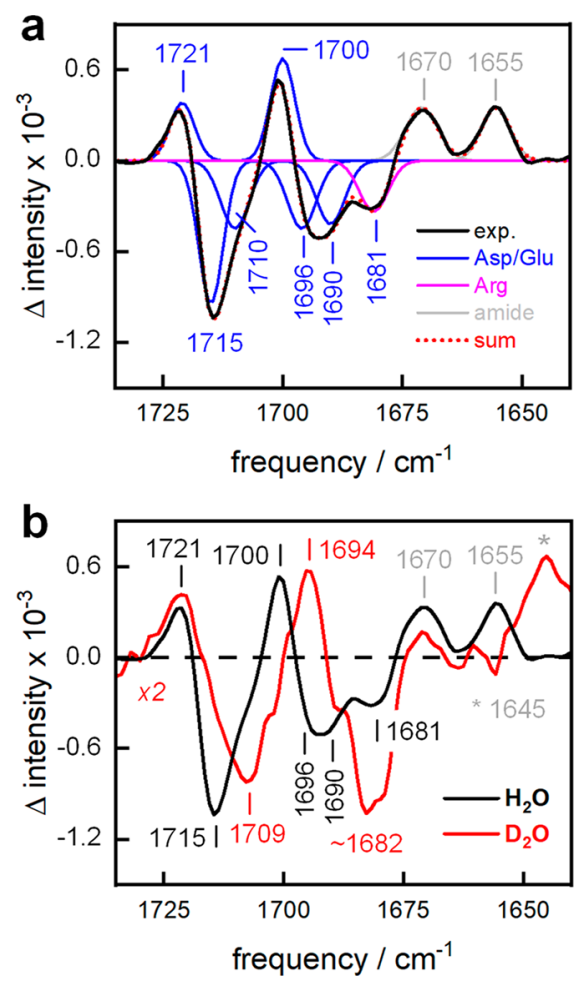

Figure 3. Band fit and H/D exchange. (a) The experimental ATR FTIR difference spectrum of the Hred - Hox conversion (black) was fitted with a minimum of six Gaussians in the $\mathrm{COOH}$ regime of aspartic or glutamic acid residues (blue), a single band that may stem from the $\mathrm{C}\left(\mathrm{NH}_{2}\right)_{3}{ }^{+}$vibration of an arginine (magenta), and two contributions in the amide regime (gray). The red dotted line depicts the resulting sum of fits. (b) Comparison of ATR FTIR difference spectra on hydrated and deuterated film (black and red, respectively). The data indicate a downshift of $6-14 \mathrm{~cm}^{-1}$ for bands associated with Hox (negative intensities) and similar frequency difference for bands accumulating upon reduction (positive intensities). No significant shift was noted for the positive bands at 1721 and $\sim 1670 \mathrm{~cm}^{-1}$.

cluster (Figure S1). Vibrations at frequencies greater than 1700 $\mathrm{cm}^{-1}$ are typically assigned to the $\mathrm{C}=\mathrm{O}$ stretches of the $\mathrm{COOH}$ side chain from aspartic acid or glutamic acid residues (E, D). ${ }^{57,59}$ The $\mathrm{C}=\mathrm{O}$ stretching frequency is inversely proportional to the hydrogen-bonding strength and can vary between none to multiple hydrogen-bonding partners from 1750 to $1700 \mathrm{~cm}^{-1}$. Besides clearly discriminable bands at 1721,1715 , and $1700 \mathrm{~cm}^{-1}$ our fit routine suggested additional contributions centered at 1710, 1696, 1690, and 1681 (Figure $3 a)$. The negative band at $1681 \mathrm{~cm}^{-1}$ may be attributed to the asymmetric $\mathrm{C}\left(\mathrm{NH}_{2}\right)_{3}{ }^{+}$vibration of the protonated arginine side chain, ${ }^{60-62}$ while the broader features at $\sim 1670$ and 1655 $\mathrm{cm}^{-1}$ potentially arise from changes in amide I absorbance. ${ }^{63}$ The latter likely reflects minor changes in secondary structure induced upon reduction of the H-cluster.

H/D Exchange. To achieve an experimental band assignment in the $\mathrm{COOH}$ regime, we performed photoreduction on hydrated and deuterated hydrogenases films. Bands indicative of hydrogen bonding or protonation changes involving the carboxylic side chains are supposed to shift to lower frequencies in deuterated sample. ${ }^{63}$ Absorbance spectra of the HYDA1/5CE/EDTA reaction mixture show a complete exchange of solvent in the presence of either $\mathrm{H}_{2} \mathrm{O}$ or $\mathrm{D}_{2} \mathrm{O}$, and Hred - Hox difference spectra prove that deuteration did not affect the $\mathrm{H}$-clusters' $\mathrm{CO} / \mathrm{CN}^{-}$band position (Figure S5).
However, in the $\mathrm{COOH}$ regime, the spectra show significant changes (Figure $3 \mathrm{~b}$ ). The prominent H/D shift of 1715 and $1700 \mathrm{~cm}^{-1}$ to 1709 and $1694 \mathrm{~cm}^{-1}$ immediately supports an assignment of this motif to a titratable group, for example, an aspartic or glutamic acid side chain. Bands at 1696 and 1690 $\mathrm{cm}^{-1}$ were affected by the $\mathrm{H} / \mathrm{D}$ shift as well. While a dissection of components is not immediately possible here, the mean frequency downshift by $12 \pm 2 \mathrm{~cm}^{-1}$ suggests strongly hydrogen-bonded aspartic or glutamic acid side chains. ${ }^{57,59}$ The positive band at $1721 \mathrm{~cm}^{-1}$ is insensitive to $\mathrm{H} / \mathrm{D}$ exchange.

To achieve an unambiguous experimental band assignment, we analyzed three amino acid variants of the proton transfer pathway, namely, R148A, E144D, and S189A. The enrichment of Hred over Hox depends on functional proton transfer. ${ }^{33-35}$ In particular, amino acid residues C169 and E141 close to the $\mathrm{H}$-cluster were found to be susceptible to variations of the hydrogen-bonding network, slowly accumulating the hydride state Hhyd over Hox rather than Hred (Figure S6). This impedes a direct comparison, and only a limited number of variants allowed screening the hydrogen-bonding changes associated with catalytic proton transfer. An invariable hydrogen-bonding network between H-cluster and E141 is in striking agreement with the aforementioned lack of hydrogenbonding changes around W1 and C169 (Figure S4). Relative to the H-cluster, we will refer to C169, W1, and E141 as "inner core" of the proton transfer pathway.

By contrast, Figure 4 shows Hred - Hox difference spectra of HYDA1 variants that constitute the "outer core" of the proton transfer pathway, namely, R148, E144, and S189. Sitedirected mutagenesis at these positions included an exchange against alanine (A). No accumulation of Hred was observed upon photoreduction of E144A (Figure S6) so that the conservative variation of glutamic to aspartic acid was analyzed instead. Variants R148A, E144D, and S189A adopted Hred upon illumination but showed only $15-25 \%$ of the native conversion efficiency (Figure S7). For comparison with native HYDA1, difference spectra were normalized to the amplitude of the band pair at 1715 and $1700 \mathrm{~cm}^{-1}$ that was found to be prominently conserved in all spectra. The resulting scaling factors were in good agreement with the amplitudes observed for the $\mathrm{CO}$ difference bands of the conversion of Hred over Hox. Figure S6 depicts the spectral transitions over time for each variant including an evaluation of signal-to-noise in the $\mathrm{COOH}$ regime.

Amino Acid Variant R148A. The $\mathrm{H}_{2}$ evolution activity of $\sim 50 \%$ for HYDA1 variant R148A indicates that glutamic acid E144 can partially replace R148 as proton loading site. ${ }^{42}$ Figure 4a shows an overlay of Hred - Hox difference spectra in the $\mathrm{COOH}$ regime for R148A and native HYDA1 (left panel). The right panel depicts an overlay of the respective CPI crystal structures. For the sake of convenience, we will use HYDA1 numbering here. Site-directed mutagenesis resulted in spectra with missing features at 1721, 1696, or $1681 \mathrm{~cm}^{-1}$ (marked "X"), while the shift from 1715 to $1700 \mathrm{~cm}^{-1}$ and a negative band at $1690 \mathrm{~cm}^{-1}$ was conserved.

Above, we tentatively assigned the negative feature at 1681 $\mathrm{cm}^{-1}$ to the asymmetric $\mathrm{C}\left(\mathrm{NH}_{2}\right)_{3}{ }^{+}$vibration of an arginine residue. ${ }^{60-62}$ The evident lack of this band in amino acid variant R148A supports this assignment. Moreover, the band at $1681 \mathrm{~cm}^{-1}$ shifted to $1607 \mathrm{~cm}^{-1}$ in deuterated sample, which is in excellent agreement to guanidine hydrochloride $H / D$ reference spectra in Figure 5. Therefore, we conclude 


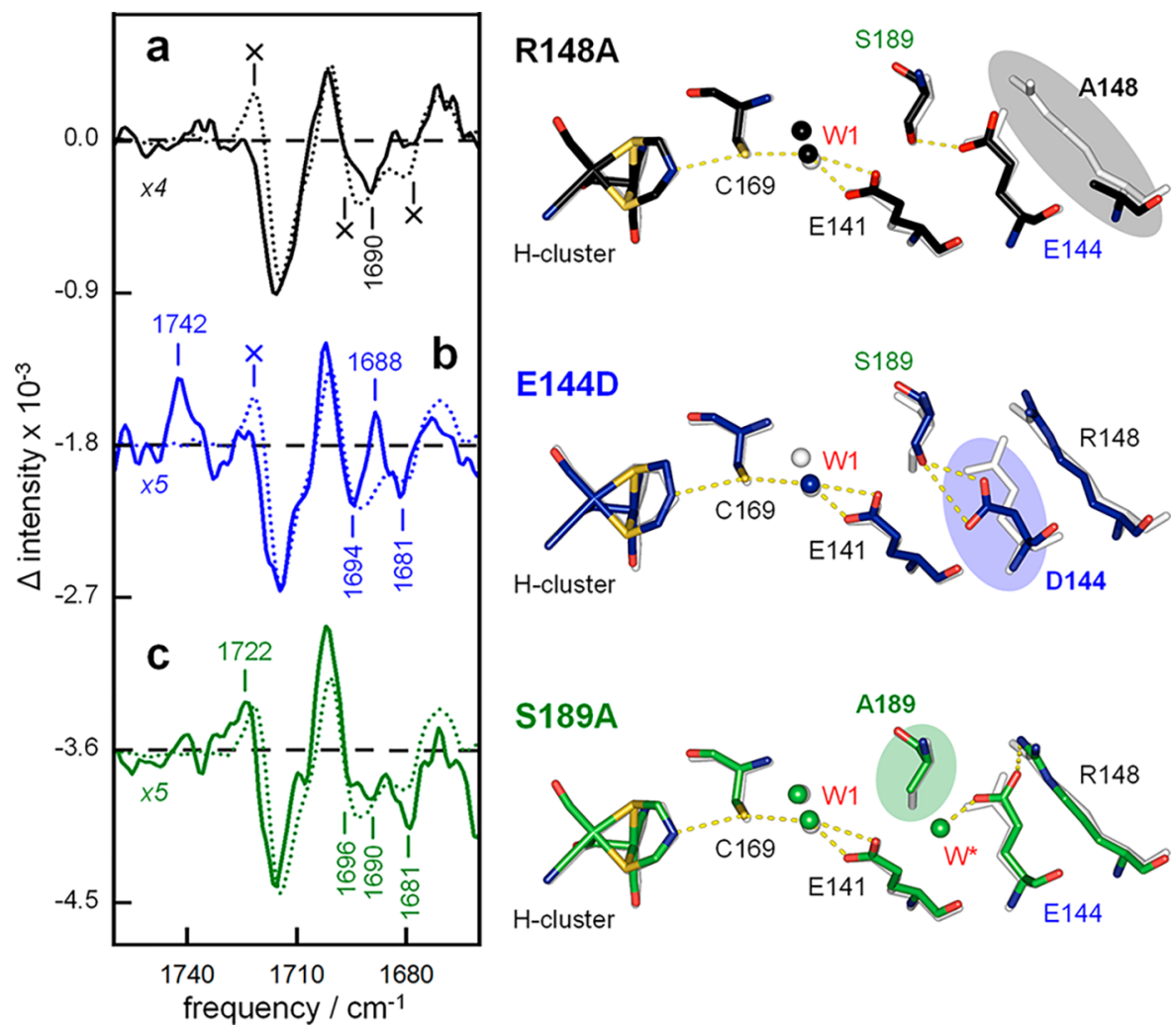

Figure 4. Spectral and structural differences between native [FeFe]-hydrogenase and three variants. (left) The in situ ATR FTIR difference spectra for three different amino acid variants compared to native HYDAl (dotted traces, scaled to the 1715/1700 difference signal that was observed in all experiments). The crystallographic comparison on the right side includes CPI coordinates 4XDC, 6GM2, 6GM3, and 6GM4. (a) Arginine variant R148A lacks the positive $1721 \mathrm{~cm}^{-1}$ feature and shows significantly diminished contributions at 1696 and $1681 \mathrm{~cm}^{-1}$ ("X"). (b) Glutamic acid variant E144D exhibits an $\sim 21 \mathrm{~cm}^{-1}$ upshift of the native $1721 \mathrm{~cm}^{-1}$ band to $1742 \mathrm{~cm}^{-1}$. Negative bands at 1692 and $1682 \mathrm{~cm}^{-1}$ suggest similarities with native enzyme, whereas the band intensity at $1688 \mathrm{~cm}^{-1}$ is inverted. (c) The difference spectrum of serine variant $\mathrm{S} 189 \mathrm{~A}$ indicates a largely native behavior with only smaller differences in band intensity. See Figure S7 for further details.

deprotonation of $\mathrm{R} 148^{+}$upon formation of Hred in native HYDA1. Poisson-Boltzmann calculations predicted a $\mathrm{p} K_{\mathrm{a}}$ of $\sim 3.5$ for E144 in native HYDA1 (Table S1). Although our experiments were conducted at $\mathrm{pH} 6$, we suggest hydrogen bonding of E144 to R148 ( 2.8 $\AA$ ) and S189 ( 3.1 $\AA)$ stabilizing the carboxylic over the carboxylate form of E144. However, the carboxylate form likely prevails in the absence of the arginine side chain. The lack of spectral features at 1721 and $1696 \mathrm{~cm}^{-1}$ in the R148A difference spectrum (X) therefore facilitates the assignment to hydrogen-bonding changes involving E144 in native HYDA1.

Glutamic Acid Variant E144D. As observed for the arginine variant, the interaction between R148 and E144 (E144D) is not strictly essential for catalytic activity. Amino acid variant $\mathrm{E} 144 \mathrm{D}$ is reported with $\sim 50 \% \mathrm{H}_{2}$ evolution activity. ${ }^{42}$ Figure $4 \mathrm{~b}$ shows an overlay of Hred - Hox difference spectra in the $\mathrm{COOH}$ regime for R144D and native HYDA1 (left panel). The right panel depicts an overlay of the respective CPI crystal structures. ${ }^{42}$ Site-directed mutagenesis resulted in spectra with a pronounced band upshift from 1721 to $1742 \mathrm{~cm}^{-1}$ and an intensity inversion of the band at $\sim 1690$ $\mathrm{cm}^{-1}$ (negative in native HYDA1, slightly shifted and positive in E144D). The band pair at 1715 and $1700 \mathrm{~cm}^{-1}$ and negative bands at 1694 and $1681 \mathrm{~cm}^{-1}$ are conserved among variant and native HYDA1.

Shortening of the alkyl side chain at position 144 causes a different hydrogen-bonding situation (Figure $4 b$, right panel). Instead of forming a hydrogen bond with R148 ( 5.0 Å) rotation of the aspartic acid side chain forces D144 into a weak complex with S189 in Hox (3.0 and 3.7 $\AA$ ) that reflects in a $\mathrm{p} K_{\mathrm{a}}$ increase of nearly three units compared to native HYDA1 (Table S1). The upshift of the E144 band from 1721 to 1742 $\mathrm{cm}^{-1}$ suggests significantly weaker hydrogen bonding in reduced enzyme. Furthermore, variant E144D allows differentiating the $1696 / 1690 \mathrm{~cm}^{-1}$ peak doublet. The latter band appears positive in the spectrum, and thus only the $1696 \mathrm{~cm}^{-1}$ band is assigned to E144.

Serine Variant S189A. Figure $4 c$ shows an overlay of Hred - Hox difference spectra in the $\mathrm{COOH}$ regime for S189A and native HYDA1 (left panel). The right panel depicts an overlay of the respective CPI crystal structures. ${ }^{42}$ Despite the relatively low $\mathrm{H}_{2}$ evolution activity of $\sim 10 \%$, site-directed mutagenesis resulted in spectra indicative of only minor differences to native HYDA1. The crystal structure of the S189A variant revealed an additional water molecule $\left(\mathrm{W}^{*}\right)$ between E144 and E141 (Figure 4c, right panel). This arrangement was proposed to compensate the lack of the serine side chain. ${ }^{42}$ E144 is in fair hydrogen-bonding distance to $\mathrm{W}^{*}(\sim 2.4 \AA)$ and $\mathrm{R} 148(\sim 2.9 \AA)$, which largely restores the spectral phenotype of native HYDA1. However, the distance of 5.8 $\AA$ between E141 and $\mathrm{W}^{*}$ is clearly out of range for hydrogen bonding or proton transfer.

Glutamic Acid E141. The band pair at 1715 and 1700 $\mathrm{cm}^{-1}$ is prominently conserved in all protein samples that accumulate Hred over Hox. The H/D specific band shift hints at a carboxylic group and suggests efficient proton exchange; 

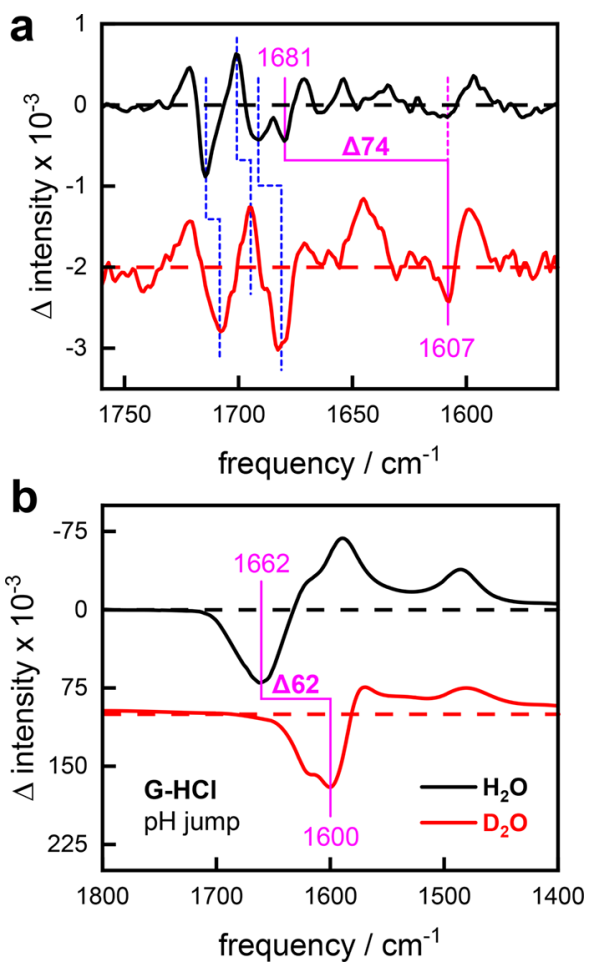

Figure 5. Experimental assignment of arginine R148. (a) Comparison of Hred - Hox difference spectra on hydrated and deuterated film (black and red, respectively) as in Figure 3. Isotope downshifts associated with $\mathrm{COOH}$ group are indicated by blue dashes. The band at $1681 \mathrm{~cm}^{-1}$ was tentatively assigned to the protonated guanidinium headgroup of $\mathrm{R} 148^{+}$. In the presence of $\mathrm{D}_{2} \mathrm{O}$, a negative feature at $1607 \mathrm{~cm}^{-1}$ was observed, most likely representing the deuterated arginine. (b) $\mathrm{pH}$ jump experiments on guanidine- $\mathrm{HCl}$ solved in $\mathrm{H}_{2} \mathrm{O}$ (black) or $\mathrm{D}_{2} \mathrm{O}$ (red). The difference spectra depict deprotonation of the guanidinium ion (negative bands) at $\mathrm{pH} \approx 14$. Both the absolute band positions and the H/D-specific downshift closely match the Hred - Hox difference spectrum in (a).

however, the motif could not be assigned to E144. Residing in a hydrophobic pocket at the interface of inner and outer core of the proton transfer pathway, glutamic acid E141 has been calculated to adopt the carboxylic acid form for $\mathrm{pH}$ values less than $8 .^{42}$ Accordingly, changes associated with E141 will be visible in the $\mathrm{COOH}$ regime. ${ }^{57}$ Any variation of E141 abolished catalytic activity and the formation of Hred (Figure S5) hinting at the central role of E141 in proton transfer. On the basis of this line of evidence, we assign the band pair at 1715 and $1700 \mathrm{~cm}^{-1}$ to E141. Figure S7 provides a conclusive overview on the observed frequencies and experiment band assignment.

The $\mathrm{C}=\mathrm{O}$ stretching frequencies of glutamic acid E141 indicate strong hydrogen-bonding contacts, irrespective of redox state. ${ }^{57,59}$ To this end, the crystal structure of oxidized enzyme supports a trans complex between E141 and W1 (distances 2.4 and $3.4 \AA$ ). ${ }^{64-66}$ The $15 \mathrm{~cm}^{-1}$ frequency downshift upon reduction may reflect a release of the E141/ W1 complex in favor of hydrogen bonding with S189 (or W* in serine variant S189A). This demands a certain level of structural flexibility, as the distance between E141 and S189 amounts to $\sim 3.8 \AA$ in oxidized enzyme. Molecular dynamics simulations showed that E141 and S189 change between hydrogen-bonding donor and acceptor when switching from proton uptake to proton release. ${ }^{43,45}$ Apparently, smaller structural changes at the interface of inner and outer core are well within the thermodynamic range of functional $[\mathrm{FeFe}]$ hydrogenases. The large distance between E141 and $\mathrm{W}^{*}$ (5.8 $\AA$ ) reduces the probability of proton transfer in serine variant S189A to $\sim 10 \% \mathrm{H}_{2}$ release activity. ${ }^{42}$ The experimental assignment of our data is summed up in Figure 6 and Table 1.

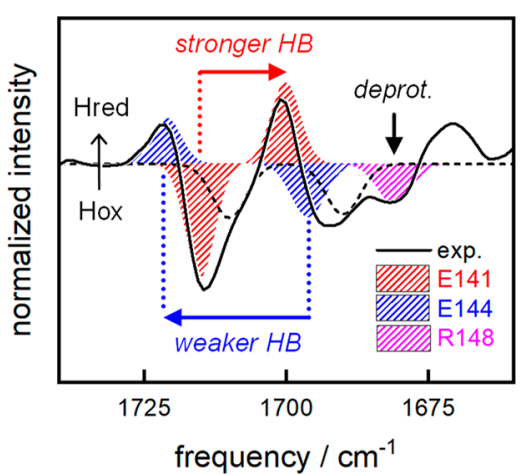

Figure 6. Band assignment. Our analysis of native [FeFe]hydrogenase in $\mathrm{H}_{2} \mathrm{O}$ and $\mathrm{D}_{2} \mathrm{O}$ as well as seven different amino acid variants implies a downshift of the band at $1715 \mathrm{~cm}^{-1}$ by $14 \mathrm{~cm}^{-1}$ (red) and an upshift of the band at $1696 \mathrm{~cm}^{-1}$ by $25 \mathrm{~cm}^{-1}$ (blue). The former is assigned to E141 suggesting stronger hydrogen bonding in Hred. The latter is assigned to E144 suggesting the loss of a hydrogen-bonding partner (weaker hydrogen bonding). The negative band at $1681 \mathrm{~cm}^{-1}$ (magenta) is assigned to deprotonation of $\mathrm{R} 148^{+}$ upon formation of Hred. No conclusive assignment is available for the bands at 1710 and $1690 \mathrm{~cm}^{-1}$ (dashed traces).

Table 1. Band Assignment ${ }^{a}$

$\begin{array}{lcllll}v, \mathrm{~cm}^{-1} & \text { redoxstate } & \text { residue } & \text { H-bonds } & \text { donor } & \text { acceptor } \\ 1742 * & \text { Hred } & \text { D144 } & \text { none } & & \\ 1721 & \text { Hred } & \text { E144 } & \text { single } & \text { S189 } & \\ 1715 & \text { Hox } & \text { E141 } & \text { double } & \text { W1 } & \\ 1700 & \text { Hred } & \text { E141 } & \text { double } & \text { W1 } & \text { S189 } \\ 1696 & \text { Hox } & \text { E144 } & \text { double } & \text { R148 } & \text { S189 } \\ 1681 & \text { Hox } & {\mathrm{R} 148^{+}}^{*} & \text { single } & & \text { E144 }\end{array}$

${ }^{a}$ IR frequencies $(v)$ refer to native HYDA1 except as noted $(*)$. The identity of hydrogen-bonding partners differs between amino acid variants.

\section{DISCUSSION}

Figure $7 \mathrm{a}$ depicts the progression of amino acid residues involved in catalytic proton transfer as identified in the crystal structure of oxidized $[\mathrm{FeFe}]$-hydrogenase (Hox). ${ }^{42}$ This arrangement favors proton uptake and $\mathrm{H}_{2}$ evolution. Arginine $\mathrm{R} 148^{+}$donates a hydrogen bond to glutamic acid E144 (3.1 $\AA$ ), the latter forming a hydrogen bond with serine S189 (2.8 $\AA){ }^{43-45}$ On the basis of $\mathrm{pK}$ a calculations, we previously favored an ionic bond between $\mathrm{R} 148^{+}$and the carboxylate of E144; ${ }^{42}$ however, such stabilization fails to explain the FTIR band changes. Trapped between R148 and S189, E144 likely persists in protonated, carboxylic acid form, even at $\mathrm{pH}$ values well above the predicted $\mathrm{p} K_{\mathrm{a}}$ of 3.5 (Table S1).

Serine S189 is located at the interface of inner and outer core of the proton transfer pathway, as defined above. The distance of $\sim 3.8 \AA$ between $\mathrm{S} 189$ and E141 does reflect discontinued hydrogen bonding, and the probability of proton transfer appears insufficient to justify turnover frequencies greater than $10000 \mathrm{H}_{2} \mathrm{~s}^{-1}$. ${ }^{9-11}$ The crystal structure supports 


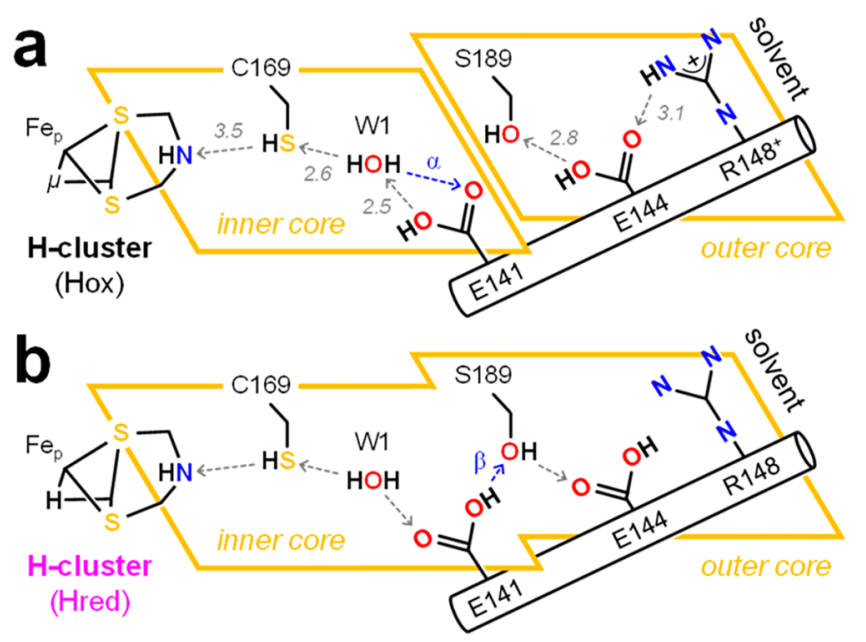

Figure 7. The hydrogen-bonding network of the catalytic proton transport pathway. (a) Progression of amino acid residues as observed in the crystal structure of oxidized [FeFe]-hydrogenase CPI (Hox). All distances refer to pdb coordinates 4XDC (HYDAl numbering). Our data suggest hydrogen-bonding contacts between S189, E144, and R148 ${ }^{+}$of the catalytic proton transport pathway. Furthermore, invariable hydrogen bonding between ADT, C169, and W1 was observed. The W1/E141 complex establishes the difference between inner and outer core of the catalytic proton transport pathway. (b) In reduced [FeFe]-hydrogenase (Hred), the W1/141 complex is terminated in favor of hydrogen bonding between E141, S189, and E144, which facilitates continuous proton transfer (see main text for details). Our data indicate deprotonation of $\mathrm{R} 148^{+}$upon formation of Hred.

E141 and water molecule W1 forming a trans complex that represents the most stable configuration of $\mathrm{COOH}$ groups in aqueous solution. ${ }^{64-66}$ This arrangement would interrupt the catalytic hydrogen-bonding network as indicated by the yellow boxes in Figure 7. The E141/W1 complex is weakened by the relatively long donor distance $(\alpha=3.4 \AA)$, which may alleviate changing from W1 to S189 as hydrogen-bond acceptor, for example, upon reduction of the H-cluster.

Our IR data are compatible with subtle structural changes upon formation of Hred. Figure $7 \mathrm{~b}$ illustrates how the catalytic proton transfer pathway between active site cofactor and solvent is significantly more continuous in the reduced enzyme. The downshift of the E141 band may reflect dissolution of the E141/W1 complex and hydrogen bonding to $\mathrm{S} 189$ with $\alpha>\beta$ (in the oxidized crystal, $\beta$ is $0.4 \AA$ larger than $\alpha$; see Figure 7a). Serine S189 donates a single bond to E144; however, no second hydrogen bond is formed by E144 due to deprotonation of $\mathrm{R} 148^{+}$. This is in agreement with the pronounced upshift of the E144 band. We assume that a reprotonation of $\mathrm{R} 148$ is precluded by the unfavorable local electrostatics betweenE144 and $\mathrm{R} 148^{+}$. Our data support a model in which the E144/R148 interface is defined by the $\mathrm{OH}$ donor group of the E144 side chain, held in place by a hydrogen bond from S189 (Figure $7 \mathrm{~b}$ ). Formation of R148 appears to be hindered in the presence of a potential hydrogenbonding donor. The stability of deprotonated arginine residues in proteins has been questioned ${ }^{67}$ and, to our knowledge, has not been observed before. Yet, our spectroscopic investigation on hydrated and deuterated [ $\mathrm{FeFe}]$-hydrogenase clearly allows concluding deprotonation of $\mathrm{R} 148^{+}$upon reduction of the enzyme. This conserved arginine functions as proton donor to the active site cofactor, fine-tuning proton transfer efficiency and catalytic bias.

The mechanism of discontinuous proton transfer conceptualized above likely includes a transient step we can speculate about now. Reduction of the $\mathrm{H}$-cluster by one electron leads to an increase in basicity and the formation of Hred upon protonation via the catalytic proton transfer pathway. On the basis of the lack of difference signals in the $\mathrm{SH}$ and $\mathrm{OH}$ regime, we consider a rigid donor/acceptor conformation between the H-cluster, C169, and W1. Protonation of the ADT headgroup in Hred was discussed $^{33-35}$ and computed earlier, ${ }^{43-45}$ but the present data do not support steady-state protonation changes at the ADT headgroup, cysteine thiolate, or water cluster. Transiently, however, formation of Hred may trigger deprotonation of E141 (Figure S8). In a second step, the high basicity of E141 ${ }^{-}$ would induce steady-state deprotonation of $\mathrm{R} 148^{+}$, proton transfer via E144 and S189, and reprotonation of E141, now hydrogen-bonded to S189 instead of W1 (Figure 7b).

\section{CONCLUSIONS}

In this work, we demonstrate how in situ infrared spectroscopy was applied to analyze the hydrogen-bonding network of the catalytic proton transfer pathway in $[\mathrm{FeFe}]$-hydrogenases. Discontinuous proton transfer was triggered by the enhanced basicity of the active site cofactor (H-cluster) upon photoreduction of a highly active iron-sulfur enzyme lacking a natural chromophore. Infrared spectroscopy provides a direct read-out for changes in hydrogen bonding perfectly complementary to X-ray crystallography. Thereby, the first experimental description of the dynamic hydrogen-bonding changes in the catalytic proton transfer pathway of [FeFe]-hydrogenases was accomplished.

Discontinuous proton transfer is common in nature, for example, in retinal proteins, ${ }^{68,69}$ photosystem $\mathrm{II},{ }^{70}$ cytochrome $c$ oxidase, ${ }^{71}$ and other systems, ${ }^{48,72}$ but it has not yet been considered in hydrogenases. Our model rationalizes how ions transcend the gap between inner and outer core of the proton transfer pathway. Furthermore, it provides a reasonable explanation for the catalytic bidirectionality of $[\mathrm{FeFe}]$ hydrogenases. ${ }^{6-8}$ Glutamic acid E141 switches as hydrogenbonding donor between W1 (proton uptake) and S189 (proton release). Deviations in distance less than $0.5 \AA$ suggest a flexible hydrogen-bonding network that facilitates both $\mathrm{H}_{2}$ evolution (proton uptake) and $\mathrm{H}_{2}$ oxidation (proton release).

\section{ASSOCIATED CONTENT}

\section{Supporting Information}

The Supporting Information is available free of charge on the ACS Publications website at DOI: 10.1021/jacs.9b09225.

Band fitting and kinetic description; spectral characteristics of the photosensitizers; $\mathrm{COOH}$ band changes; spectral transitions over time; $\mathrm{H} / \mathrm{D}$ exchange; accumulation of Hhyd; comparison of $\mathrm{CO} / \mathrm{CN}$ and $\mathrm{COOH}$ difference spectra; assignment of hydrogen-bonding changes; hypothetical intermediate of proton transfer; Propka calculations (PDF)

\section{AUTHOR INFORMATION}

\section{Corresponding Author}

*sven.stripp@fu-berlin.de 


\section{ORCID $\odot$}

Jifu Duan: 0000-0002-5158-2253

Günther Knör: 0000-0002-2259-6496

Ulf-Peter Apfel: 0000-0002-1577-2420

Thomas Happe: 0000-0003-1206-5234

Joachim Heberle: 0000-0001-6321-2615

Sven Timo Stripp: 0000-0002-8412-0258

\section{Notes}

The authors declare no competing financial interest.

\section{ACKNOWLEDGMENTS}

We thank all reviewers for their valuable input. This project was supported by the following agencies: Deutsche Forschungsgemeinschaft (DFG) through the priority program 1927 to S.T.S. (grant 1554/5-1), the SFB 1078, and Cluster of Excellence UniSysCat to J.H. T.H., M.W., and J.D. are grateful for funding from Cluster of Excellence RESOLV (EXC2033, project 390677874), the DFG Training Group GRK 2341 Microbial Substrate Conversion (MiCon), Volkswagen Stiftung (Design of $[\mathrm{FeS}]$ cluster containing MetalloDNAzymes, $\mathrm{Az}$ 93412), and the China Scholarship Council. G.K. acknowledges funding by the Austrian Science Fund (FWF, project DK W-1250 B20).

\section{REFERENCES}

(1) Lubitz, W.; Ogata, H.; Rudiger, O.; Reijerse, E. Hydrogenases. Chem. Rev. 2014, 114 (8), 4081-4148.

(2) Vignais, P. M.; Billoud, B. Occurrence, Classification, and Biological Function of Hydrogenases: An Overview. Chem. Rev. 2007, 107 (10), 4206-4272.

(3) Thauer, R. K.; Kaster, A.-K.; Goenrich, M.; Schick, M.; Hiromoto, T.; Shima, S. Hydrogenases from Methanogenic Archaea, Nickel, a Novel Cofactor, and H2 Storage. Annu. Rev. Biochem. 2010, 79, 507-536.

(4) Fritsch, J.; Lenz, O.; Friedrich, B. Structure, Function and Biosynthesis of O2-Tolerant Hydrogenases. Nat. Rev. Microbiol. 2013, 11 (2), 106-114.

(5) Peters, J. W.; Schut, G. J.; Boyd, E. S.; Mulder, D. W.; Shepard, E. M.; Broderick, J. B.; King, P. W.; Adams, M. W. [FeFe]- and [NiFe]-Hydrogenase Diversity, Mechanism, and Maturation. Biochim. Biophys. Acta, Mol. Cell Res. 2015, 1853 (6), 1350-1369.

(6) Stripp, S. T.; Happe, T. How Algae Produce Hydrogen - News from the Photosynthetic Hydrogenase. Dalt. Trans. 2009, 45, 99609969.

(7) Wittkamp, F.; Senger, M.; Stripp, S. T.; Apfel, U.-P. [FeFe]Hydrogenases: Recent Developments and Future Perspectives. Chem. Commun. 2018, 54, 5934-5942.

(8) Fourmond, V.; Wiedner, E. S.; Shaw, W. J.; Leger, C. On the Understanding and Design of Bidirectional and Reversible Catalysts Of. J. Am. Chem. Soc. 2019, 141 (28), 11269-11285.

(9) Vincent, K. A.; Parkin, A.; Armstrong, F. A. Investigating and Exploiting the Electrocatalytic Properties of Hydrogenases. Chem. Rev. 2007, 107 (10), 4366-4413.

(10) Greco, C.; Fourmond, V.; Baffert, C.; Wang, P.; Dementin, S.; Bertrand, P.; Bruschi, M.; Blumberger, J.; De Gioia, L.; Léger, C. Combining Experimental and Theoretical Methods to Learn about the Reactivity of Gas-Processing Metalloenzymes. Energy Environ. Sci. 2014, 7, 3543-3573.

(11) Armstrong, F. A.; Evans, R. M.; Hexter, S. V.; Murphy, B. J.; Roessler, M. M.; Wulff, P. Guiding Principles of Hydrogenase Catalysis Instigated and Clarified by Protein Film Electrochemistry. Acc. Chem. Res. 2016, 49 (5), 884-892.

(12) Barton, B. E.; Olsen, M. T.; Rauchfuss, T. B. Artificial Hydrogenases. Curr. Opin. Biotechnol. 2010, 21 (3), 292-297.
(13) Simmons, T. R.; Berggren, G.; Bacchi, M.; Fontecave, M.; Artero, V. Mimicking Hydrogenases: From Biomimetics to Artificial Enzymes. Coord. Chem. Rev. 2014, 270-271 (1), 127-150.

(14) Möller, F.; Piontek, S.; Miller, R. G.; Apfel, U.-P. From Enzymes To Functional Materials - Towards Activation Of Small Molecules. Chem. - Eur. J. 2018, 24 (7), 1471-1493.

(15) Peters, J. W.; Lanzilotta, W. N.; Lemon, B. J.; Seefeldt, L. C. XRay Crystal Structure of the Fe-Only Hydrogenase (CpI) from Clostridium Pasteurianum to 1.8 Angstrom Resolution. Science 1998, 282 (5395), 1853-1858.

(16) Nicolet, Y.; Piras, C.; Legrand, P.; Hatchikian, C. E.; FontecillaCamps, J. C. Desulfovibrio Desulfuricans Iron Hydrogenase: The Structure Shows Unusual Coordination to an Active Site Fe Binuclear Center. Structure 1999, 7 (1), 13-23.

(17) Esselborn, J.; Muraki, N.; Klein, K.; Engelbrecht, V.; MetzlerNolte, N.; Apfel, U.-P.; Hofmann, E.; Kurisu, G.; Happe, T. A Structural View of Synthetic Cofactor Integration into $[\mathrm{FeFe}]$ Hydrogenases. Chem. Sci. 2016, 7, 959-968.

(18) Pierik, A. J.; Hulstein, M.; Hagen, W. R.; Albracht, S. P. A LowSpin Iron with $\mathrm{CN}$ and $\mathrm{CO}$ as Intrinsic Ligands Forms the Core of the Active Site in [Fe]-Hydrogenases. Eur. J. Biochem. 1998, 258 (2), 572-578.

(19) De Lacey, A. L.; Stadler, C.; Cavazza, C.; Hatchikian, E. C.; Fernandez, V. M. FTIR Characterization of the Active Site of the FeHydrogenase from Desulfovibrio Desulfuricans. J. Am. Chem. Soc. 2000, 122 (45), 11232-11233.

(20) Nicolet, Y.; De Lacey, A. L.; Vernède, X.; Fernandez, V. M.; Hatchikian, E. C.; Fontecilla-Camps, J. C. Crystallographic and FTIR Spectroscopic Evidence of Changes in $\mathrm{Fe}$ Coordination upon Reduction of the Active Site of the Fe-Only Hydrogenase from Desulfovibrio Desulfuricans. J. Am. Chem. Soc. 2001, 123 (8), 15961601.

(21) Silakov, A.; Wenk, B.; Reijerse, E.; Lubitz, W. 14N HYSCORE Investigation of the $\mathrm{H}$-Cluster of [FeFe] Hydrogenase: Evidence for a Nitrogen in the Dithiol Bridge. Phys. Chem. Chem. Phys. 2009, 11 (31), 6592 .

(22) Duan, J.; Mebs, S.; Laun, K.; Wittkamp, F.; Heberle, J.; Hofmann, E.; Apfel, U.-P.; Winkler, M.; Senger, M.; Haumann, M.; Stripp, S. T.; et al. Geometry of the Catalytic Active Site in [FeFe]Hydrogenase Is Determined by Hydrogen Bonding and Proton Transfer. ACS Catal. 2019, 9, 9140-9149.

(23) Albracht, S. P. J.; Roseboom, W.; Hatchikian, E. C. The Active Site of the $[\mathrm{FeFe}]$-Hydrogenase from Desulfovibrio Desulfuricans. I. Light Sensitivity and Magnetic Hyperfine Interactions as Observed by Electron Paramagnetic Resonance. JBIC, J. Biol. Inorg. Chem. 2006, 11 (1), 88-101.

(24) Roseboom, W.; De Lacey, A. L.; Fernandez, V. M.; Hatchikian, E. C.; Albracht, S. P. J. The Active Site of the $[\mathrm{FeFe}]$-Hydrogenase from Desulfovibrio Desulfuricans. II. Redox Properties, Light Sensitivity and CO-Ligand Exchange as Observed by Infrared Spectroscopy. JBIC, J. Biol. Inorg. Chem. 2006, 11 (1), 102-118.

(25) Silakov, A.; Reijerse, E. J.; Albracht, S. P. J.; Hatchikian, E. C.; Lubitz, W. The Electronic Structure of the H-Cluster in the $[\mathrm{FeFe}]$ Hydrogenase from Desulfovibrio Desulfuricans: A Q-Band 57FeENDOR and HYSCORE Study. J. Am. Chem. Soc. 2007, 129 (37), 11447-11458.

(26) Katz, S.; Noth, J.; Horch, M.; Shafaat, H. S.; Happe, T.; Hildebrandt, P.; Zebger, I. Vibrational Spectroscopy Reveals the Initial Steps of Biological Hydrogen Evolution. Chem. Sci. 2016, 7, 6746-6752.

(27) Senger, M.; Mebs, S.; Duan, J.; Shulenina, O.; Laun, K.; Kertess, L.; Wittkamp, F.; Apfel, U.-P.; Happe, T.; Winkler, M.; Haumann, M.; Stripp, S. T. Protonation/Reduction Dynamics at the [4Fe-4S] Cluster of the Hydrogen-Forming Cofactor in [FeFe]Hydrogenases. Phys. Chem. Chem. Phys. 2018, 20, 3128-3140.

(28) Mulder, D. W.; Ratzloff, M. W.; Bruschi, M.; Greco, C.; Koonce, E.; Peters, J. W.; King, P. W. Investigations on the Role of Proton-Coupled Electron Transfer in Hydrogen Activation by 
[FeFe]-Hydrogenase. J. Am. Chem. Soc. 2014, 136 (43), 1539415402 .

(29) Mulder, D. W.; Guo, Y.; Ratzloff, M. W.; King, P. W. Identification of a Catalytic Iron-Hydride at the $\mathrm{H}$-Cluster of $[\mathrm{FeFe}]$ Hydrogenase. J. Am. Chem. Soc. 2017, 139 (1), 83-86.

(30) Winkler, M.; Senger, M.; Duan, J.; Esselborn, J.; Wittkamp, F.; Hofmann, E.; Apfel, U.-P.; Stripp, S. T.; Happe, T. Accumulating the Hydride State in the Catalytic Cycle of [FeFe]-Hydrogenases. Nat. Commun. 2017, 8 (16115), 1-7.

(31) Reijerse, E. J.; Pham, C. C.; Pelmenschikov, V.; Gilbert-Wilson, R.; Adamska-Venkatesh, A.; Siebel, J. F.; Gee, L. B.; Yoda, Y.; Tamasaku, K.; Lubitz, W.; Rauchfuss, T. B.; Cramer, S. P. Direct Observation of an Iron-Bound Terminal Hydride in [FeFe]Hydrogenase by Nuclear Resonance Vibrational Spectroscopy. J. Am. Chem. Soc. 2017, 139 (12), 4306-4309.

(32) Senger, M.; Laun, K.; Wittkamp, F.; Duan, J.; Haumann, M.; Happe, T.; Winkler, M.; Apfel, U.-P.; Stripp, S. T. Proton-Coupled Reduction of the Catalytic $[4 \mathrm{Fe}-4 \mathrm{~S}]$ Cluster in $[\mathrm{FeFe}]$-Hydrogenases. Angew. Chem., Int. Ed. 2017, 56 (52), 16503-16506.

(33) Adamska-Venkatesh, A.; Silakov, A.; Lambertz, C.; Rüdiger, O.; Happe, T.; Reijerse, E.; Lubitz, W. Identification and Characterization of the "Super-Reduced" State of the H-Cluster in [FeFe] Hydrogenase: A New Building Block for the Catalytic Cycle? Angew. Chem., Int. Ed. 2012, 51 (46), 11458-11462.

(34) Sommer, C.; Adamska-Venkatesh, A.; Pawlak, K.; Birrell, J. A.; Rüdiger, O.; Reijerse, E. J.; Lubitz, W. Proton Coupled Electronic Rearrangement within the $\mathrm{H}$-Cluster as an Essential Step in the Catalytic Cycle of [FeFe] Hydrogenases. J. Am. Chem. Soc. 2017, 139 (4), 1440-1443.

(35) Mebs, S.; Senger, M.; Duan, J.; Wittkamp, F.; Apfel, U.-P.; Happe, T.; Winkler, M.; Stripp, S. T.; Haumann, M. Bridging Hydride at Reduced H-Cluster Species in [FeFe]-Hydrogenases Revealed by Infrared Spectroscopy, Isotope Editing, and Quantum Chemistry. J. Am. Chem. Soc. 2017, 139 (35), 12157-12160.

(36) Haumann, M.; Stripp, S. T. The Molecular Proceedings of Biological Hydrogen Turnover. Acc. Chem. Res. 2018, 51 (8), 17551763.

(37) Ratzloff, M. W.; Artz, J. H.; Mulder, D. W.; Collins, R. T.; Furtak, T. E.; King, P. W. CO-Bridged H-Cluster Intermediates in the Catalytic Mechanism of [FeFe]-Hydrogenase CaI. J. Am. Chem. Soc. 2018, 140 (24), 7623-7628.

(38) Fourmond, V.; Greco, C.; Sybirna, K.; Baffert, C.; Wang, P.-H.; Ezanno, P.; Montefiori, M.; Bruschi, M.; Meynial-Salles, I.; Soucaille, P.; Blumberger, J.; Bottin, H.; De Gioia, L.; Léger, C. The Oxidative Inactivation of FeFe Hydrogenase Reveals the Flexibility of the $\mathrm{H}$ Cluster. Nat. Chem. 2014, 6 (4), 336-342.

(39) Cornish, A. J.; Gärtner, K.; Yang, H.; Peters, J. W.; Hegg, E. L. Mechanism of Proton Transfer in [FeFe]-Hydrogenase from Clostridium Pasteurianum. J. Biol. Chem. 2011, 286, 38341-38347.

(40) Morra, S.; Giraudo, A.; Di Nardo, G.; King, P. W.; Gilardi, G.; Valetti, F. Site Saturation Mutagenesis Demonstrates a Central Role for Cysteine 298 as Proton Donor to the Catalytic Site in CaHydA [FeFe]-Hydrogenase. PLoS One 2012, 7 (10), No. e48400.

(41) Cornish, A. J.; Ginovska, B.; Thelen, A.; Da Silva, J. C. S.; Soares, T. A.; Raugei, S.; Dupuis, M.; Shaw, W. J.; Hegg, E. L. SingleAmino Acid Modifications Reveal Additional Controls on the Proton Pathway of [FeFe]-Hydrogenase. Biochemistry 2016, 55 (22), 31653173.

(42) Duan, J.; Senger, M.; Esselborn, J.; Engelbrecht, V.; Wittkamp, F.; Apfel, U.-P.; Hofmann, E.; Stripp, S. T.; Happe, T.; Winkler, M. Crystallographic and Spectroscopic Assignment of the Proton Transfer Pathway in [FeFe]-Hydrogenases. Nat. Commun. 2018, 9, 4726.

(43) Long, H.; King, P. W.; Chang, C. H. Proton Transport in Clostridium Pasteurianum [FeFe] Hydrogenase I: A Computational Study. J. Phys. Chem. B 2014, 118 (4), 890-900.

(44) Sode, O.; Voth, G. a. Electron Transfer Activation of a Second Water Channel for Proton Transport in [FeFe]-Hydrogenase. J. Chem. Phys. 2014, 141 (22), 22 D527.
(45) Ginovska-Pangovska, B.; Ho, M.-H.; Linehan, J. C.; Cheng, Y.; Dupuis, M.; Raugei, S.; Shaw, W. J. Molecular Dynamics Study of the Proposed Proton Transport Pathways in [FeFe]-Hydrogenase. Biochim. Biophys. Acta, Bioenerg. 2014, 1837 (1), 131-138.

(46) Garczarek, F.; Gerwert, K. Functional Waters in Intraprotein Proton Transfer Monitored by FTIR Difference Spectroscopy. Nature 2006, 439, 216-219.

(47) Debus, R. J. FTIR Studies of Metal Ligands, Networks of Hydrogen Bonds, and Water Molecules near the Active Site $\mathrm{Mn} 4 \mathrm{CaO} 5$ Cluster in Photosystem II. Biochim. Biophys. Acta, Bioenerg. 2015, 1847 (1), 19-34.

(48) Kottke, T.; Lórenz-Fonfría, V. A.; Heberle, J. The Grateful Infrared: Sequential Protein Structural Changes Resolved by Infrared Difference Spectroscopy. J. Phys. Chem. B 2017, 121, 335-350.

(49) Lübben, M.; Gerwert, K. Redox FTIR Difference Spectroscopy Using Caged Electrons Reveals Contributions of Carboxyl Groups to the Catalytic Mechanism of Haem-Copper Oxidases. FEBS Lett. 1996, 397 (2-3), 303-307.

(50) Adam, D.; Bösche, L.; Castaneda-Losada, L.; Winkler, M.; Apfel, U.-P.; Happe, T. Sunlight-Dependent Hydrogen Production by Photosensitizer/Hydrogenase Systems. ChemSusChem 2017, 10, 894-902.

(51) Esselborn, J.; Lambertz, C.; Adamska-Venkatesh, A.; Simmons, T.; Berggren, G.; Noth, J.; Siebel, J. F.; Hemschemeier, A.; Artero, V.; Reijerse, E.; Fontecave, M.; Lubitz, W.; Happe, T. Spontaneous Activation of $[\mathrm{FeFe}]-$ Hydrogenases by an Inorganic [2Fe] Active Site Mimic. Nat. Chem. Biol. 2013, 9, 607-609.

(52) Berggren, G.; Adamska-Venkatesh, A.; Lambertz, C.; Simmons, T. R.; Esselborn, J.; Atta, M.; Gambarelli, S.; Mouesca, J.-M.; Reijerse, E. J.; Lubitz, W.; Happe, T.; Artero, V.; Fontecave, M. Biomimetic Assembly and Activation of [FeFe]-Hydrogenases. Nature 2013, 499 (7456), 66-69.

(53) Senger, M.; Mebs, S.; Duan, J.; Wittkamp, F.; Apfel, U.-P.; Heberle, J.; Haumann, M.; Stripp, S. T. Stepwise Isotope Editing of [FeFe]-Hydrogenases Exposes Cofactor Dynamics. Proc. Natl. Acad. Sci. U. S. A. 2016, 113 (30), 8454-8459.

(54) Knör, G. The Concept of Photochemical Enzyme Models State of the Art. Coord. Chem. Rev. 2016, 325, 102-115.

(55) Kandori, H. Role of Internal Water Molecules in Bacteriorhodopsin. Biochim. Biophys. Acta, Bioenerg. 2000, 1460 (1), 177-191.

(56) Lórenz-Fonfría, V. A.; Muders, V.; Schlesinger, R.; Heberle, J. Changes in the Hydrogen-Bonding Strength of Internal Water Molecules and Cysteine Residues in the Conductive State of Channelrhodopsin-1. J. Chem. Phys. 2014, 141 (22), 22 D507.

(57) Barth, A. The Infrared Absorption of Amino Acid Side Chains. Prog. Biophys. Mol. Biol. 2000, 74 (3-5), 141-173.

(58) Tai, H.; Nishikawa, K.; Higuchi, Y.; Mao, Z.-W.; Hirota, S. Cysteine $\mathrm{SH}$ and Glutamate $\mathrm{COOH}$ Contributions to $[\mathrm{NiFe}]$ Hydrogenase Proton Transfer Revealed by Highly Sensitive FT-IR Spectroscopy. Angew. Chem., Int. Ed. 2019, 58 (38), 13285-13290.

(59) Nie, B.; Stutzman, J.; Xie, A. A Vibrational Spectral Maker for Probing the Hydrogen-Bonding Status of Protonated Asp and Glu Residues. Biophys. J. 2005, 88 (4), 2833-2847.

(60) Jones, W. J. The Infra-Red Spectrum and Structure of Guanidine. Trans. Faraday Soc. 1959, 55, 524-527.

(61) Venyaminov, S. Y.; Kalnin, N. N. Quantitative IR Spectrophotometry of Peptide Compounds in Water (H2O) Solutions. I. Spectral Parameters of Amino Acid Residue Absorption Bands. Biopolymers 1990, 30 (13-14), 1243-1257.

(62) Braiman, M. S.; Briercheck, D. M.; Kriger, K. M. Modeling Vibrational Spectra of Amino Acid Side Chains in Proteins: Effects of Protonation State, Counterion, and Solvent on Arginine C-N Stretch Frequencies ${ }^{\dagger}$. J. Phys. Chem. B 1999, 103 (22), 4744-4750.

(63) Barth, A. Infrared Spectroscopy of Proteins. Biochim. Biophys. Acta, Bioenerg. 2007, 1767 (9), 1073-1101.

(64) Priem, D.; Ha, T. K.; Bauder, A. Rotational Spectra and Structures of Three Hydrogen-Bonded Complexes between Formic Acid and Water. J. Chem. Phys. 2000, 113 (1), 169-175. 
(65) Aloisio, S.; Hintze, P. E.; Vaida, V. The Hydration of Formic Acid. J. Phys. Chem. A 2002, 106 (2), 363-370.

(66) Müller-Dethlefs, K.; Hobza, P. Noncovalent Interactions: A Challenge for Experiment and Theory. Chem. Rev. 2000, 100 (1), 143-168.

(67) Harms, M. J.; Schlessman, J. L.; Sue, G. R.; Garcia-Moreno, B. Arginine Residues at Internal Positions in a Protein Are Always Charged. Proc. Natl. Acad. Sci. U. S. A. 2011, 108 (47), 18954-18959.

(68) Lorenz-Fonfria, V. A.; Resler, T.; Krause, N.; Nack, M.; Gossing, M.; Fischer von Mollard, G.; Bamann, C.; Bamberg, E.; Schlesinger, R.; Heberle, J. Transient Protonation Changes in Channelrhodopsin-2 and Their Relevance to Channel Gating. Proc. Natl. Acad. Sci. U. S. A. 2013, 110 (14), E1273-E1281.

(69) Lorenz-Fonfria, V. A.; Saita, M.; Lazarova, T.; Schlesinger, R.; Heberle, J. PH-Sensitive Vibrational Probe Reveals a Cytoplasmic Protonated Cluster in Bacteriorhodopsin. Proc. Natl. Acad. Sci. U. S. A. 2017, 114 (51), E10909-E10918.

(70) McEvoy, J. P.; Brudvig, G. W. Water-Splitting Chemistry of Photosystem II. Chem. Rev. 2006, 106 (11), 4455-4483.

(71) Nyquist, R. M.; Heitbrink, D.; Bolwien, C.; Gennis, R. B.; Heberle, J. Direct Observation of Protonation Reactions during the Catalytic Cycle of Cytochrome c Oxidase. Proc. Natl. Acad. Sci. U. S. A. 2003, 100 (15), 8715-8720.

(72) Ishikita, H.; Saito, K. Proton Transfer Reactions and HydrogenBond Networks in Protein Environments. J. R. Soc., Interface 2014, 11 (91), 20130518. 